\title{
Evaluation of Water, Sanitation, and Hygiene, Behavioral Aspects, Household State for the Diarrhea Prevalence among Students in the Valley of Sinabung Volcano, North Sumatera, Indonesia
}

\author{
Nenni Dwi Aprianti Lubis (iD) ${ }^{1 *}$, Sri Amelia $\mathbb{D}^{2}$, Hemma Yulfi $\mathbb{D}^{3}$, Merina Panggabean ${ }^{3}{ }^{3}$, Muhammad Fakhrur Rozi ${ }^{4}$ \\ ${ }^{1}$ Department of Nutrition, Faculty of Medicine, Universitas Sumatera Utara, Medan, Indonesia; ${ }^{2}$ Department of Microbiology, \\ Faculty of Medicine, Universitas Sumatera Utara, Medan, Indonesia; ${ }^{3}$ Department of Parasitology, Faculty of Medicine, \\ Universitas Sumatera Utara, Medan, Indonesia
}

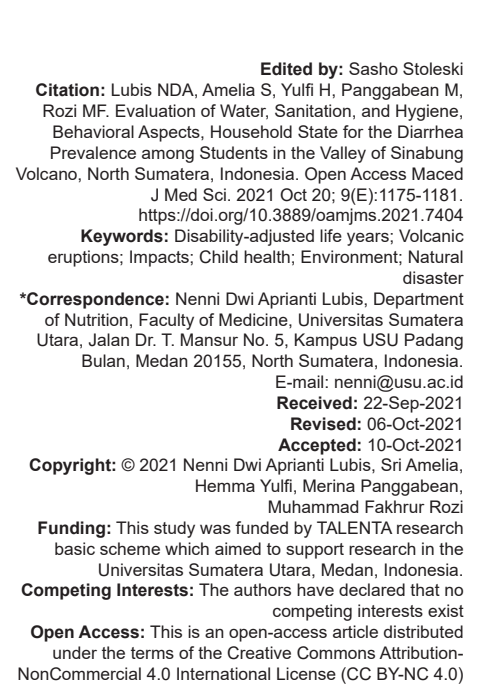

\section{Abstract}

BACKGROUND: Diarrhea stands as a result of the inter-variable relationships, including behavior, environmental aspect, and household states.

AIM: The study aimed to conduct an epidemiologic survey of diarrhea prevalence and several existing risk factors of diarrhea.

METHODS: A community-based surveillance and in-depth interview were conducted following the JMP ladder service for Water, Sanitation, and Hygiene (WASH) and government regulation and it enrolled 135 children of a public primary school, SDN 040494, and households in the Valley of Sinabung Volcano, North Sumatera, Indonesia, between June and October 2019. There were only two lowest categories of each WASH indicator.

RESULTS: Multivariate analysis has also demonstrated a high likelihood of diarrhea among the population in limited settings for hygiene $(p=0.012$, AOR 7.892 , and $95 \% \mathrm{Cl} 2.485,25.064)$ and low daily income $(p=0.015$, AOR 3.079 , and $95 \% \mathrm{Cl} 1.148,8.260)$.

CONCLUSION: Hygiene and daily income have significant association with diarrhea prevalence. Improvement of hygienic practices is mandatory as well as preventing volcanic eruption implications to the economy of the local community.

\section{Introduction}

Diarrhea is one of the most devastating symptoms associated with gastrointestinal or systemic illnesses. It usually manifests as a result of excessive water secretion in gut lumen caused by both infectious or noninfectious agents and it could be transmitted through oral ingestion in contaminated food, drinking water, or directly from person-to-person [1], [2]. Diarrhea poses a threat to high-risk populations resulting in higher mortality, such as infants, elderly, and immunocompromised individuals, since it can cause dehydration, water, and electrolyte imbalance as well as bloody discharge, excessive sweating, high-grade fever, and vomiting [3].

Morbidity and mortality associated with diarrhea also considered high in several countries. Based on the global data registry, diarrhea accounts for 525,000 deaths, with approximately 1.7 billion new cases of diarrheal episodes each year, and it also ranks as the leading killer in children under 4 years old [4]. In addition, children also reportedly suffer from three-episode diarrhea each year in low-income countries [5]. In Indonesia, it is estimated that diarrhea produced 10-24 deaths per 100,000 people in 2016, while the peak mortality occurred among adults older than 70 years old, 200-299 deaths per 100,000 people. In total, disability-adjusted life-years (DALYs) of diarrhea per 1000 children younger than 5 years old are 86.7, with a considerable increase in long-term sequelae during these decades [6].

There are several factors relating to the occurrence of diarrhea ranging from personal behavioral factors, environmental variables, infrastructure, and natural disasters, but one is sure that diarrhea is still a preventable and treatable clinical entity. In other regions, significant incidence or outbreaks occur mainly 
as a result of poor hygiene and sanitation [7]. Therefore, the World Health Organization (WHO) focuses on the intervention for safe drinking water, improved sanitation, and hygiene, termed as Water-Sanitation-Hygiene (WASH) [8]; the program targeted to 780 million people with lack access of improved drinking water as well as 2.5 billion with unimproved sanitation. In addition, young age [9], washing hands before feeding, and after visiting latrine, unsafe sources of drinking water while living in a rural area and malnourished are the other risk factors related to diarrhea [10], [11]. In Ethiopia, infrastructure problems and discrepancies between urban areas promoted diarrhea among children, followed by poor sanitation and hygiene behavior. Open waste disposal and lack of latrine also expose the children to environmental contamination [12].

Delayed development of infrastructure in rural areas, particularly in former or ongoing natural disaster prone-area, is another factor associated with a higher incidence of infectious diseases among children [13]. Furthermore, natural disaster affects physical integrity of the population and environment merely because of rapid displacement, overcrowding in refugee centers, lack of infrastructure for safe drinking water and sanitation, and limited healthcare services [14]. Sinabung Volcano, one of the most active volcanoes in Indonesia, starts erupting from 2010, and it is relentlessly doing so until today, before that it was dormant for about 400 years. There are several natural disasters in the location, such as volcanic eruption, cold lava flooding, ash and gas emissions, and landslide occurred as a result of insistent volcano activities between 2010 and 2020 [15], [16]; however, no data relating to health impacts of this natural disaster on the local prevalence of infectious diseases.

Thus, the study objective aimed to conduct an epidemiologic survey of diarrhea prevalence and its associated risk factors among primary school students in the base of Sinabung Volcano, North Sumatera, Indonesia.

\section{Methods}

\section{Study location and design}

The study location was in Susuk Village, Sub-district Tiganderket, Karo, North Sumatera, Indonesia. Based on the data registry of Central Bureau of Statistics of Karo District, Susuk also covers an area of $8.50 \mathrm{~km}^{2}$ northwest base of Mount Sinabung and contained 1,583 people with a population density of 186.24 per $\mathrm{km}^{2}$ within the close perimeter to the volcano which erupted in the previous 10 years. This is a community-based observational and cross-sectional study conducted in a three-stage process, pre-implementation, implementation, and final evaluation between June and October 2019. The study was initiated from a public primary school of Tiganderket, SDN 040494 Susuk, Karo District. There were 137 primary school students in the school; each student was a representative for his/her respective household and consented for investigation.

\section{Data collection}

A research team observed the school and households and conducted in-depth interviews with students, schoolstake-holder, and officials in government and primary care centers. General characteristics of respondents included sociodemographic aspects, both mother/caretaker and children. Meanwhile, mother/caretakers were interviewed for child behavior and preliminary household condition in addition to direct observation for child misbehavior. History or recent diarrhea in the previous 14 days was noted as dependent variables (the criteria were based on the World Health Organization definition for diarrhea; the presence of loose or watery diarrhea for minimum 3 times a day) [17]. All mothers/caretakers must require to participate in a brief introduction of the study to conceive a similar understanding about independent variables, and all indicators were also structured based on official guidelines released from the WHO in 2016; core question and indicators for monitoring WASH in schools in the Sustainable Development Goals [17].

\section{Independent variables}

Independent variables such as general characteristics (child gender, age, nutritional status based on body mass index per age, and parasitic fecal examination), and behavioral aspects were also evaluated through the study. Sociodemographic data in parental aspects were included mother/caretaker's age, education level, family size, daily income (based on provincial minimum labor salary rate), and caretaker occupation. In addition, children behavior relating to hand-washing, defecation, nail hygiene (CDC recommendation), soil contact, daily consumption of food (Ministry of Agriculture recommended food with adequate nutritional value, that was varied, balanced, safe, and healthy) [18], bathing, and teeth brushing frequency included as the other independent variables. All selected independent variables have been notably related to diarrhea occurrence in the previous study based on multivariate logistic regression and structural equation modeling (SEM) or descriptively discovered higher in diarrheal population.

Assessment of the WASH indicator was directed against each household and interpreted in accordance with the WHO indicators for the fulfillment of the emerging Joint Monitoring Program (JMP) service ladder in the Sustainable Development Goals (SDGs) [17]. This consisted of safely managed, basic, 
limited, and improved service and limited service for drinking water and sanitation indicators, such as basic, limited and no facility for hygiene indicators. Nevertheless, there were only two lowest categories in each indicator obtained during the preliminary study. By definition, drinking water is categorized as "basic service" when drinking water sources of an improved container are available; an improved source (piped, water, protected well, and rainwater) but no water during the survey listed as "limited service." In sanitation, the presence of improved facilities (flush/ pour flush and pit latrine with slab) is defined as "limited service" and no toilet or other facilities for "no service." Meanwhile, hygiene quality is scrutinized based on the availability of hand-washing facilities and grouped into "basic service" (water and soap were available) and no soap as "limited service." Meanwhile, garbage disposal, source of drinking water, and ownership of latrine were also disclosed for the position as independent variables of the other household states, in addition to the WASH indicators.

\section{Data analysis}

Independent and dependent variables were collected in one period time of the survey in the study locations. One investigator entered the raw data into Microsoft Excel before the statistical analysis using SPSS (Statistical Package for Social Science) version 24. General characteristics of children and parents/caretakers were analyzed descriptively before undergoing bivariate analyzes using the Chi-square test; the output was determined whether $p<0.25$ was achieved, thus all included variables were adjusted into multivariable logistic regression. This study was approved by the Ethical Committee for Medical Research, Faculty of Medicine, Universitas Sumatera Utara, Medan, Indonesia (Reference No. 391/TGL/ KEPK FK USU-RSUP HAM/2019 on May 16, 2019).

\section{Results}

\section{General characteristics}

This study was conducted in the base of Sinabung Volcano, North Sumatera province, which had been actively erupting in recent years. The survey was carried out in one of the public primary schools in the valley and each student will be selected to represent their household. Consequently, it was obtained that there was a total of 137 primary school students (all students in the primary school). They automatically enrolled into the study after their caretakers signed informed consent, but there were four siblings admittedly live in one household, later two students were excluded from the study. There was no parasitic infection after the duplex routine parasitic examinations in the parasitology laboratory; therefore, this variable has failed to join the analysis. Child age was then divided into two categories based on the median of the numerical data and young age students, which grouped in 7-10 years old was higher $(63.7 \%)$ with no gender predominance (Table 1). Grade proportion was different in three groups: The smallest number of respondents in the first and second grades (25.9\%). In addition, there were more than $90 \%$ of students with normal nutritional status, but inadequate daily income was found among $76.3 \%$ of the families in the study. Farming also becomes one of the primary caretaker occupations, with a percentage of $72.6 \%$. Smaller family size (3-5 people) was predominant and more than 50\% caretaker's age was in the group of 25-39 years old.

Table 1: General characteristics of respondents

\begin{tabular}{|c|c|c|c|}
\hline Variables & Indicators & Frequency & Percent \\
\hline \multirow{2}{*}{ Children age } & $7-10$ & 86 & 63.7 \\
\hline & $11-14$ & 49 & 36.3 \\
\hline \multirow[t]{2}{*}{ Gender } & Male & 69 & 51.1 \\
\hline & Female & 66 & 48.9 \\
\hline \multirow[t]{3}{*}{ Grade } & I-II & 35 & 25.9 \\
\hline & III-IV & 52 & 38.5 \\
\hline & $\mathrm{V}-\mathrm{VI}$ & 48 & 35.6 \\
\hline \multirow[t]{2}{*}{ Nutritional status } & Underweight & 11 & 8.1 \\
\hline & Normal & 124 & 91.9 \\
\hline \multirow[t]{2}{*}{ Caretaker education level } & Primary school & 53 & 39.3 \\
\hline & Secondary school or higher & 82 & 60.7 \\
\hline \multirow[t]{2}{*}{ Daily income } & Inadequate & 103 & 76.3 \\
\hline & Adequate & 32 & 23.7 \\
\hline \multirow[t]{3}{*}{ Caretaker age } & $25-39$ years & 70 & 51.9 \\
\hline & $40-54$ years & 61 & 45.2 \\
\hline & over 55 years & 4 & 3.0 \\
\hline \multirow[t]{3}{*}{ Caretaker occupation } & Farming & 98 & 72.6 \\
\hline & Housewife & 22 & 16.3 \\
\hline & Others & 15 & 11.1 \\
\hline \multirow[t]{2}{*}{ Family size } & $3-5$ & 90 & 66.7 \\
\hline & over 5 people & 45 & 33.3 \\
\hline
\end{tabular}

\section{Children's behavior}

These categories span from personal hygiene and daily food consumption. Adequacy of food consumption followed the criteria from government regulations and found that $64.4 \%$ of children inadequately provided for food consumption (Table 2). Poor nail hygiene has been discovered in $57 \%$ of children with infrequent nail-biting behavior. Living in the rural region also forced children to help their parents farming; consequently, almost $50 \%$ of children were categorized with frequent soil contact.

Table 2: Children behavioral aspects

\begin{tabular}{llcc}
\hline Variables & Indicators & Frequency & Percent \\
\hline Nail hygiene & Poor & 77 & 57.0 \\
& Good & 58 & 43.0 \\
Nail-biting & Infrequent & 123 & 91.1 \\
& Frequent & 12 & 8.9 \\
Soil contact & Infrequent & 71 & 52.6 \\
& Frequent & 64 & 47.4 \\
Hand-washing & Water+Soap & 63 & 56.7 \\
& Water only & 72 & 53.3 \\
Bathing frequency per day & Once & 17 & 12.6 \\
& Twice & 118 & 87.4 \\
Teeth brushing per day & Once & 41 & 30.4 \\
& Twice & 94 & 69.6 \\
Food consumption & Inadequate & 87 & 64.4 \\
& Adequate & 48 & 35.6 \\
\hline
\end{tabular}




\section{Household states and WASH evaluation}

A direct evaluation of the household was conducted for 1 week in the village. However, there was a significant finding of the WASH indicators; in each indicator; there were only two categories for water, sanitation, and hygiene. Nevertheless, almost all households were in the minimum criteria for WASH with water and hygiene was mostly in basic service, and sanitation has the two lowest categories based on the JMP service ladder. Other household states, such as garbage disposal, ownership of latrine, and source of drinking water, were also depicted in Table 3.

Table 3: WASH indicators and other household states

\begin{tabular}{llcc}
\hline Variables & Indicators & Frequency & Percent \\
\hline Water & Limited service & 4 & 3.0 \\
& Basic service & 131 & 97.0 \\
Sanitation & No service & 34 & 25.2 \\
& Limited service & 101 & 74.8 \\
Hygiene & Limited service & 21 & 15.6 \\
& Basic service & 114 & 84.4 \\
Garbage disposal & Yes & 64 & 47.4 \\
& No & 71 & 52.6 \\
Ownership of latrine & Private & 49 & 36.3 \\
& Shared & 86 & 63.7 \\
Source of drinking water & Wells & 47 & 34.8 \\
& Filtered water & 42 & 31.1 \\
& Spring & 46 & 34.1 \\
\hline
\end{tabular}

\section{Diarrheal-associated risk factors}

Data analysis was performed in a two-stage process, firstly a Chi-square test $(p<0.25$ indicated variables for subsequent analysis using logistic regression). Child's gender, daily income, food consumption, and other variables with suitable p-value were included in second stage analysis and multivariate logistic regression (Table 4). Furthermore, it was evident through the final analysis that daily income and hygiene were significantly associated with diarrhea occurrence in the study population $(p=0.015$ and 0.012 ,

Table 4: Multivariate logistic regression results

\begin{tabular}{|c|c|c|c|c|c|}
\hline \multirow[t]{2}{*}{$\begin{array}{l}\text { General } \\
\text { characteristics }\end{array}$} & \multicolumn{2}{|c|}{$\begin{array}{l}\text { Diarrhea } \\
\text { occurrence }\end{array}$} & \multirow[t]{2}{*}{$p$-value } & \multirow[t]{2}{*}{$95 \% \mathrm{Cl}$} & \multirow[t]{2}{*}{ Adjusted 95\% Cl } \\
\hline & Yes & No & & & \\
\hline \multicolumn{6}{|l|}{ Child gender } \\
\hline Male & $24(34.8)$ & $45(65.2)$ & 0.099 & 1 & \\
\hline Female & $30(45.5)$ & $36(54.4)$ & & $0.469(0.191,1.154)$ & \\
\hline \multicolumn{6}{|l|}{ Caretaker age } \\
\hline $25-39$ & $22(31.4)$ & $48(68.6)$ & 0.103 & 1 & \\
\hline $40-54$ & $30(49.2)$ & $31(50.8)$ & & $0.506(0.223,1.149)$ & \\
\hline $\begin{array}{l}\text { over } 55 \\
\text { years old }\end{array}$ & $2(50.0)$ & $2(50.0)$ & & $0.198(0.021,1.891)$ & \\
\hline \multicolumn{6}{|l|}{ Daily income } \\
\hline Adequate & $9(28.1)$ & $23(71.9)$ & $0.015^{*}$ & 1 & \\
\hline Inadequate & 45 (43.7) & $58(56.3)$ & & $3.941(1.306,11.895)$ & $3.079(1.148,8.260)$ \\
\hline \multirow{2}{*}{\multicolumn{6}{|c|}{$\begin{array}{l}\text { Food } \\
\text { consumption }\end{array}$}} \\
\hline & & & & 1 & \\
\hline Adequate & 16 (33.3) & $32(66.7)$ & & $0.478(0.182,1.253)$ & $0.449(0.197,1.021)$ \\
\hline \multicolumn{6}{|l|}{ Teeth brushing } \\
\hline Twice & $34(36.2)$ & $60(63.8)$ & 0.153 & 1 & \\
\hline Once & $20(48.8)$ & $21(51.2)$ & & $0.502(0.195,1.293)$ & \\
\hline \multicolumn{6}{|l|}{ Sanitation } \\
\hline No service & 19 (55.9) & $15(44.1)$ & 0.211 & 1 & \\
\hline $\begin{array}{l}\text { Limited } \\
\text { service }\end{array}$ & $35(34.7)$ & $66(65.3)$ & & $1.902(0.695,5.209)$ & \\
\hline \multicolumn{6}{|l|}{ Hygiene } \\
\hline $\begin{array}{l}\text { Basic } \\
\text { service }\end{array}$ & 39 (34.2) & $75(65.8)$ & $0.012^{*}$ & 1 & \\
\hline $\begin{array}{l}\text { Limited } \\
\text { service }\end{array}$ & $15(71.4)$ & $6(28.6)$ & & $\begin{array}{l}5.465 \\
(1.444,20.679)\end{array}$ & $7.892(2.485,25.064)$ \\
\hline
\end{tabular}

respectively). Therefore, the inadequate daily income also contributed to the 4 times increase of diarrhea occurrence (AOR 3.079 and $95 \% \mathrm{Cl} 1.148,8.260$ ) in the study population as well as 5.5 times for limited service in hygiene (AOR 7.892 and $95 \% \mathrm{Cl} 2.485,25.064$ ).

\section{Discussion}

There were three major groups of independent variables in the study, sociodemographic characteristics, children's behavior, and household states, as well as WASH fulfillment observation among primary school students, households, and caretakers in the Valley of Sinabung Volcano, Susuk Village, Tiganderket subdistrict, North Sumatera. The overall diarrhea prevalence of 2 weeks was $40 \%$ ( $n=54$ students) of study populations with insignificant gender differences. Several studies also reported a high prevalence of diarrhea in certain regions worldwide. A study performed in rural Burundi found $32.6 \%$ of diarrheal prevalence whereas in other parts, Ethiopia, ranging from 9 to $36 \%$ both in rural and urban areas but there was a slight increase of diarrheal prevalence in Ghana rural areas (rural vs. urban; 17.19 vs $14.74 \%$ ) [9], [11], [19], [20]. In Indonesia, Basic Research Study 2018 (Riset Kesehatan Dasar) has registered the lower average diarrheal prevalence $(6.8 \%)$ [21]. Nevertheless, there was only a few local studies relating to diarrheal prevalence in the country; Komarulzaman et al., in 2017 discovered $14.4 \%$ prevalence while in another region showed $20.5 \%$ [22], [23].

The volcanic eruption of Sinabung appears to be one of the latent independent variables for diarrhea occurrence indirectly. It primarily affected several public facilities, such as water pipeline, electricity cut, health care service, human displacement, and economic burden (more than $70 \%$ of households were categorized as a low-income family in the study) [24], [25]. Although a direct association between diarrheal prevalence and volcanic eruption has not yet been elucidated in the study location but based on recent literature, it was notable that natural disasters are producing vulnerability for communicable disease transmission as well as diarrhea [26], [27]. Moreover, there are several primary and secondary risk factors emerged during natural disasters mainly caused by human displacement, safe water availability and sanitation facilities, underlying diseases of the affected population, and basic health service [28]. Therefore, mitigation and prevention measures must be taken place to prevent a series of public health impacts [13], [29].

In the study location, only two-lowest categories of WASH indicators had been discovered during the observation. Based on JMP ladder service 
for WASH, it was found that water and hygiene have obtained the highest implementation rate for basic service ( $97 \%$ and $84.4 \%$, respectively) compared to sanitation. The roles of maintenance water, hygiene, and sanitation have also been emphasized in alleviating diarrhea burden. In fact, WASH negligence could be associated with the emerging of many types of communicable diseases [30], [31]. Limited service of hygiene is one of the two significant independent variables demonstrated in the final analysis; it demonstrated 5 times the likelihood of children suffered from diarrhea in the limited-service group since there was more than $70 \%$ of the population suffered from diarrhea in this group.

Poor hygiene behavior has a positive impact on diarrhea prevalence. In the Gaza strip, the amalgamation of poor water quality, improper hygiene practices, and impaired sanitary facilities occurred along with acute diarrhea [32]. Whereas, poor hygiene plus uneducated caretakers poses a diarrheal threat to children in a comparative study [33]. Meanwhile, it was notable that washing hands with soap reducing diarrhea prevalence and stated as a significant risk factor for acute diarrhea prevalence in a case-control study [7]. In another hygienic perspective, children live in a house with less dirty sewage concurrent with a lower incidence of diarrhea [22], yet no significant association was found for caretakers hygienic practices and this illness. In other developing countries, there was a series of independent variables for the occurrence of acute diarrhea relating to food processing and storing, uneducated caretakers, sanitation, and improved water supply [34], [35], [36]. In Kenya, diarrhea burden was also correlated with unsafe disposal of children's feces and lower wealth index but no mention of other hygienic indicators; nevertheless, it also demonstrated the highest disability-adjusted life years (DALYs) caused by diarrhea among Sub-Saharan country [37].

In the study, it is evident that daily income has a significant association with diarrhea prevalence, accordinglymultivariatelogisticregression demonstrated that the children originate from poor daily income family is 4 times more likely to suffer from diarrhea. A study conducted in Manado, Indonesia concluded that socio-economic factors, such as caretaker educational level, family income, and savings level, play roles in affecting diarrhea incidence alongside with other caretaker characteristics [38]. Similarly, first poorest quartile of wealth index almost increases 2 times of diarrhea incidence in a rural region of Tanzania [39]. Following similar trends, the wealthiest households and rural areas linearly reduced diarrhea incidence [20]. Nevertheless, a health survey on mass media exposure and childhood diarrhea in Bangladesh failed to show any significant association between wealth index and diarrhea [40].

\section{Conclusion}

Hygiene and daily income have significant association with diarrhea prevalence. This finding indicates that there must be an improvement in hygienic practices and facilities in the Village located in the base of Sinabung Volcano to reduce the high diarrhea burden. Daily income also plays a pivotal risk factor in the study population; therefore, it should alarm the government to provide incentives to the most vulnerable people in the regions. In addition, the study also did not escape some limitations, independent variable selection could be challenging since diarrhea prevalence is not uncommon to be confounded by other risk factors.

\section{References}

1. Operario DJ, Houpt E. Defining the etiology of diarrhea: Novel approaches. Curr Opin Infect Dis. 2011;24(5):464-71. PMid:21844805

2. Walker CLF, Sack D, Black RE. Etiology of diarrhea in older children, adolescents and adults: A systematic review. PLoS Negl Trop Dis. 2010;4(8):e768. https://doi.org/10.1371/journal. pntd.0000768

PMid:20689809

3. Mokomane M, Kasvosve I, Melo Ed, Pernica JM, Goldfarb DM. The global problem of childhood diarrhoeal diseases: Emerging strategies in prevention and management. Ther Adv Infect Dis. 2018;5(1):29-43. https://doi.org/10.1177/2049936117744429 PMid:29344358

4. Megersa S, Benti T, Sahiledengle B. Prevalence of diarrhea and its associated factors among under-five children in open defecation free and non-open defecation free households in goba district southeast ethiopia: A comparative cross-sectional study. Clin Mother Child Health. 2019;16:324. https://doi. org/10.1155/2018/4271915

5. Nwaoha AF, Ohaeri CC, Amaechi EC. Prevalence of diarrhoea, and associated risk factors, in children aged 0-5 years, at two hospitals in Umuahia, Abia, Nigeria. Cuad Inv UNED. 2017;9(1):7-14. https://doi.org/10.22458/urj.v9i1.1672

6. GBD 2016 Diarrhoeal Disease Collaborators. Estimates of the global, regional, and national morbidity, mortality, and aetiologies of diarrhoea in 195 countries: A systematic analysis for the global burden of disease study 2016. Lancet Infect Dis. 2018;18(11):1211-28. https://doi.org/10.3389/fmed.2018.00011 PMid:30243583

7. Oloruntoba EO, Folarin TB, Ayede Al. Hygiene and sanitation risk factors of diarrhoeal disease among under-five children in Ibadan, Nigeria. Afr Health Sci. 2014;14(4):1001-11. https://doi. org/10.4314/ahs.v14i4.32 PMid:25834513

8. Taylor B. Effectiveness, Scale and Sustainability in WASH Programmes-a Review; 2013.

9. Alebel A, Tesema C, Temesgen B, Gebrie A, Petrucka P, Kibret GD. Prevalence and determinants of diarrhea among under-five children in Ethiopia: A systematic review and meta-analysis. PLoS One. 2018;13(6):e0199684. https://doi. 
org/10.4269/ajtmh.14-0057

PMid:29953555

10. George CM, Perin J, de Calani KJ, Norman WR, Perry H, Davis TP Jr., et al. Risk factors for diarrhea in children under five years of age residing in peri-urban communities in Cochabamba, Bolivia. Am J Trop Med Hyg. 2014;91(6):1190-6. https://doi.org/10.4269/ajtmh.14-0057 PMid:25311693

11. Melese B, Paulos W, Astawesegn FH, Gelgelu TB. Prevalence of diarrheal diseases and associated factors among underfive children in Dale district, Sidama zone, Southern Ethiopia: A cross-sectional study. BMC Public Health. 2019;19(1):1235. https://doi.org/10.1186/s12889-019-7579-2 PMid:31492123

12. Workie GY, Akalu TY, Baraki AG. Environmental factors affecting childhood diarrheal disease among under-five children in Jamma district, South Wello zone, Northeast Ethiopia. BMC Infect Dis. 2019;19(1):804. https://doi.org/10.1186/s12879-019-4445-x PMid:31519160

13. Kouadio IK, Aljunid S, Kamigaki T, Hammad K, Oshitani H Infectious diseases following natural disasters: Prevention and control measures. Expert Rev Anti Infect Ther. 2012;10(1):95-104. https://doi.org/10.1586/eri.11.155 PMid:22149618

14. Waring SC, Brown BJ. The threat of communicable diseases following natural disasters: A public health response. Disaster Manag Response. 2005;3(2):41-7. https://doi.org/10.1016/j. dmr.2005.02.003

PMid:15829908

15. Primulyana S, Kern C, Lerner AH, Saing UB, Kunrat SL, Alfianti $\mathrm{H}$, et al. Gas and ash emissions associated with the 2010-present activity of Sinabung Volcano, Indonesia. J Volcanol Geoth Res. 2019;382:184-96. https://doi. org/10.1016/j.jvolgeores.2017.11.018

16. Setiawan C, Muzani M, Warnadi W, A'Rachman F, Qismaraga Q. Analysis oflandcoverchangesaftertheeruption ofmountSinabung using satellite imagery. J Phys Conf Ser. 2019;1042(2):022108. https://doi.org/10.1088/1742-6596/1402/2/022108

17. UNICEF, WHO. Core Questions and Indicators for Monitoring WASH in Schools in the Sustainable Development Goals. Geneva, Switzerland: World Health Organization; 2016.

18. Indonesia MPR. Petunjuk Teknis Gerakan Percepatan Penganekaragaman Konsumsi Pangan. In: Agriculture, editor. Jakarta: Indonesia MPR; 2016.

19. Diouf K, Tabatabai P, Rudolph J, Marx M. Diarrhoea prevalence in children under five years of age in rural Burundi: An assessment of social and behavioural factors at the household level. Glob Health Action. 2014;7(1):24895. https://doi.org/10.3402/gha. v7.24895

\section{PMid:25150028}

20. Kumi-Kyereme A, Amo-Adjei J. Household wealth, residentia status and the incidence of diarrhoea among children under-five years in Ghana. J Epidemiol Glob Health. 2016;6(3):131-40. https://doi.org/10.1016/j.jegh.2015.05.001 PMid:26070430

21. Kemenkes R. Hasil Utama Riset Kesehatan Dasar Tahun 2018. Kementrian Kesehatan Republik Indonesia; 2018. p. 1-100.

22. Agustina R, Sari TP, Satroamidjojo S, Bovee-Oudenhoven IM, Feskens EJ, Kok FJ. Association of food-hygiene practices and diarrhea prevalence among Indonesian young children from low socioeconomic urban areas. BMC Public Health. 2013;13(1):977. https://doi. org/10.1186/1471-2458-13-977

PMid:24138899

23. Komarulzaman A, Smits J, de Jong E. Clean water, sanitation and diarrhoea in Indonesia: Effects of household and community factors. Glob Public Health. 2017;12(9):1141-55. https://doi.org/ 10.1080/17441692.2015.1127985

\section{PMid:26758565}

24. Nainggolan HL. The impact of the eruption of mount Sinabung on the socio-economic conditions of horticultural farmers in Karo regency. Sosiohumaniora. 2019;21(3):287-95. https://doi. org/10.24198/sosiohumaniora.v21i3.22382

25. Tampubolon J, Nainggolan H, Ginting A, Aritonang J. Mount Sinabung Eruption: Impact on Local Economy and Smallholder Farming in Karo Regency, North Sumatra. Paper Presented at: Proceedings of the IOP Conference Series: Earth and Environmental Science, Singapore; 2017. https://doi. org/10.1088/1755-1315/178/1/012039

26. World Health Organization. Communicable Diseases Following Natural Disasters Risk assessment and Priority Interventions, Programme on Disease Control in Humanitarian Emergencies Communicable Diseases Cluster. Geneva, Switzerland: World Health Organization; 2006. Available from: http:// www.whoint/diseasecontrol_emergencies/guidelines/cd disasters_26_06pdf [Last accessed on 2012 Feb 01]. https:// doi.org/10.2105/ccdm. 2745.015

27. Watson JT, Gayer M, Connolly MA. Epidemics after natura disasters. Emerg Infect Dis. 2007;13(1):1-5. https://doi. org/10.3201/eid1301.060779

PMid: 17370508

28. Suk JE, Vaughan EC, Cook RG, Semenza JC. Natura disasters and infectious disease in Europe: A literature review to identify cascading risk pathways. Eur $\mathrm{J}$ Public Health. 2020;30(5):928-35. https://doi.org/10.1093/eurpub/ckz111. PMid:31169886

29. Pourhosseini SS, Ardalan A, Mehrolhassani MH. Key aspects of providing healthcare services in disaster response stage. Iran $\mathrm{J}$ Public Health. 2015;44(1):111-8.

PMid:26060782

30. Joshi A, Amadi C. Impact of water, sanitation, and hygiene interventions on improving health outcomes among school children. J Environ Public Health. 2013;2013:984626. https:// doi.org/10.1155/2013/984626

PMid:24454415

31. Pickering AJ, Null C, Winch PJ, Mangwadu G, Arnold BF, Prendergast AJ, et al. The WASH Benefits and SHINE trials: Interpretation of WASH intervention effects on linear growth and diarrhoea. Lancet Glob Health. 2019;7(8):e1139-46. https://doi. org/10.1016/S2214-109X(19)30268-2

PMid:31303300

32. Abuzerr S, Nasseri S, Yunesian M, Hadi M, Zinszer $K$, Mahvi $\mathrm{AH}$, et al. Water, sanitation, and hygiene risk factors of acute diarrhea among children under five years in the Gaza Strip. J Water Sanit Hyg Dev. 2020;10(1):111-23. https://doi. org/10.2166/washdev.2019.072

33. Ehsan A, Saeed S, Ehsan F. Association of hygiene practices and diarrhea prevalence in children: A comparative study among children of educated and uneducated mothers. Pak Armed Forces Med J. 2019;69(3):617-24

34. Lubis NDA, Amelia S, Arrasyid NK, Rozi MF. Modelling of risk factors associated with foodborne disease among school-aged children in Medan, Indonesia. Open Access Maced J Med Sci. 2019;7(19):3302-6. https://doi.org/10.3889/oamjms.2019.721 PMid:31949535

35. Mshida HA, Kassim N, Kimanya ME, Mpolya E. Influence of water, sanitation, and hygiene practices on common infections among under-five children in Longido and Monduli districts of Arusha, Tanzania. J Environ Public Health. 2017;2017:9235168. https://doi.org/10.1155/2017/9235168 
PMid:29147116

36. Ramanathan M, Vijayan B. Covariates of diarrhoea among under-five children in India: Are they level dependent? PLoS One. 2019;14(8):e0221200. https://doi.org/10.1371/journal. pone.0221200

PMid:31433822

37. Mulatya DM, Ochieng C. Disease burden and risk factors of diarrhoea in children under five years: Evidence from Kenya's demographic health survey 2014. Int J Infect Dis. 2020;93:359-66. https://doi.org/10.1016/j.ijid.2020.02.003 PMid:32061860

38. Sumampouw OJ, Nelwan JE, Rumayar AA. Socioeconomic factors associated with diarrhea among under-five children in Manado Coastal area, Indonesia. J Glob Infect Dis.
2019;11(4):140-6. https://doi.org/10.4103/jgid.jgid_105_18

PMid:31849434

39. Mashoto KO, Malebo HM, Msisiri E, Peter E. Prevalence, one week incidence and knowledge on causes of diarrhea: Household survey of under-fives and adults in Mkuranga district, Tanzania. BMC Public Health. 2014;14(1):985. https:// doi.org/10.1186/1471-2458-14-985

PMid:25241912

40. Alam Z, Higuchi M, Sarker MA, Hamajima N. Mass media exposure and childhood diarrhea: A secondary analysis of the 2011 Bangladesh demographic and health survey. Nagoya J Med Sci. 2019;81(1):31-40. https://doi.org/10.18999/nagjms.81.1.31 PMid:30962653 